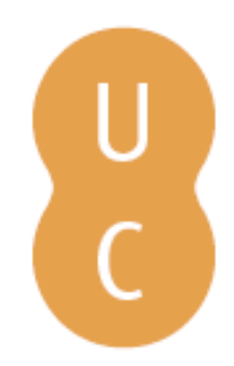

\title{
pommalina
}

\section{Os Sig e a construção de modelos territoriais no âmbito do planeamento municipal}

\author{
Autor(es): $\quad$ Ramos, Luís; Azevedo, Nuno; Bento, Ricardo; Gonçalves, Paulo
}

Publicado por: Imprensa da Universidade de Coimbra

URL

persistente: $\quad$ URI:http://hdl.handle.net/10316.2/31160

DOI: $\quad$ DOI:http://dx.doi.org/10.14195/978-989-26-0244-8_72

Accessed : $\quad$ 26-Apr-2023 10:07:18

A navegação consulta e descarregamento dos títulos inseridos nas Bibliotecas Digitais UC Digitalis, UC Pombalina e UC Impactum, pressupõem a aceitação plena e sem reservas dos Termos e Condições de Uso destas Bibliotecas Digitais, disponíveis em https://digitalis.uc.pt/pt-pt/termos.

Conforme exposto nos referidos Termos e Condições de Uso, o descarregamento de títulos de acesso restrito requer uma licença válida de autorização devendo o utilizador aceder ao(s) documento(s) a partir de um endereço de IP da instituição detentora da supramencionada licença.

Ao utilizador é apenas permitido o descarregamento para uso pessoal, pelo que o emprego do(s) título(s) descarregado(s) para outro fim, designadamente comercial, carece de autorização do respetivo autor ou editor da obra.

Na medida em que todas as obras da UC Digitalis se encontram protegidas pelo Código do Direito de Autor e Direitos Conexos e demais legislação aplicável, toda a cópia, parcial ou total, deste documento, nos casos em que é legalmente admitida, deverá conter ou fazer-se acompanhar por este aviso. 


\section{TRUNFOS DE UMA}

\section{EOGRAFIA ACIVA}

\section{DESENVOLVIMENTO LOCAL,}

AMBIENTE,

ORDENAMENTO

E TECNOLOGIA

Norberto Santos

Lúcio Cunha

COORDENAÇÃO 
Luis Ramos ${ }^{1}$, Nuno Azevedo ${ }^{12}$, Ricardo Bento, Paulo Gonçalves ${ }^{1}$

${ }^{1}$ Grupo de Estudos Territoriais - UTAD

${ }^{2}$ CEGOT, Bolseiro Doutoramento FCT (SFRH/BD/27717/2006)

\section{OS SIG E A CONSTRUÇÃO DE MODELOS TERRITORIAIS NO ÂMBITO DO PLANEAMENTO MUNICIPAL}

\section{INTRODUÇÃO}

A revisão de um Plano Director Municipal (PDM), como qualquer exercício de planeamento territorial, é um processo complexo, no qual, através de sucessivas fases de trabalho, se vai definindo um Modelo Territorial coerente para o futuro do município e se formula um conjunto de mecanismos e instrumentos (directrizes, normas, acçôes e projectos) para a concretização deste modelo (Orea, 2008). Um processo para o qual náo existe uma metodologia "standard" pois cada município tem as suas próprias especificidades, que definem uma problemática territorial concreta, e componentes socioeconómicas que o distinguem (Mclouhhlin, 1969). O ordenamento do território deve responder às circunstâncias de cada realidade.

A metodologia utilizada pelo Grupo de Estudos Territoriais (GETER) da UTAD privilegia uma abordagem sistémica, considerando o território como uma realidade complexa e agregadora de um conjunto vasto de relaçóes. Procura-se construir uma "visão" global e dinâmica do território, partindo do pressuposto de que o plano, enquanto instrumento de ordenamento, deve contribuir para conformar esta realidade ao modelo territorial que, de modo voluntário, se pretende concretizar. Nesse sentido, procura-se utilizar, sempre que possível, novas técnicas e ferramentas, raramente utilizadas em exercícios deste género, com o objectivo de alargar, aprofundar e enriquecer o âmbito e o conteúdo deste trabalho, nomeadamente os Sistema de Informação Geográfica Municipal, oportunamente criados e que nos serviram de base para muitas consideraçóes, reflexóes e orientaçóes incluídas neste documento. De forma sucinta, esta metodologia contemplou as seguintes fases (figura 1):

Fase 1 - "Fundamentos e Orientaçôes Gerais", na qual se procedeu à análise e avaliação do PDM em vigor, à caracterização da evolução recente do concelho, à avaliaçáo prévia e definição dos indicadores de qualidade ambiental e às orientaçóes e objectivos estruturantes e operacionais fixados para a revisão deste instrumento;

Fase 2 - "Estudos de Caracterização do Território Municipal”, que contemplou a análise e diagnóstico relativos aos sistemas fundamentais, e respectivos elementos estruturantes, nomeadamente: Biofísico; Urbano; Produtivo de Base Territorial. Nesta fase foi apresentado o Modelo Territorial Actual, ponto de partida para a definição das opçóes estratégicas de organização e estruturação do território; 
Fase 3 - "Proposta de Plano", a qual contemplou a elaboração de um conjunto de documentos que suportam a proposta de revisão, nomeadamente o Enquadramento e Orientações Gerais, a Visão Prospectiva e Estratégica, a Estrutura Espacial de Ordenamento, a Estrutura Espacial de Condicionantes, as Orientaçóes Regulamentares e de Gestão e o Programa de Execução.

Finalmente, importa referir a importância dada à definição do Modelo Territorial Actual, o qual juntamente com a Visão Prospectiva e Estratégica, permite delimitar o Modelo Futuro para os próximos 10 anos. É sobre a definiçáo do modelo territorial actual e a utilização do SIG municipal, de apoio à revisão do PDM, que se desenvolve este trabalho.

Figura 1 - Metodologia de revisão do PDM

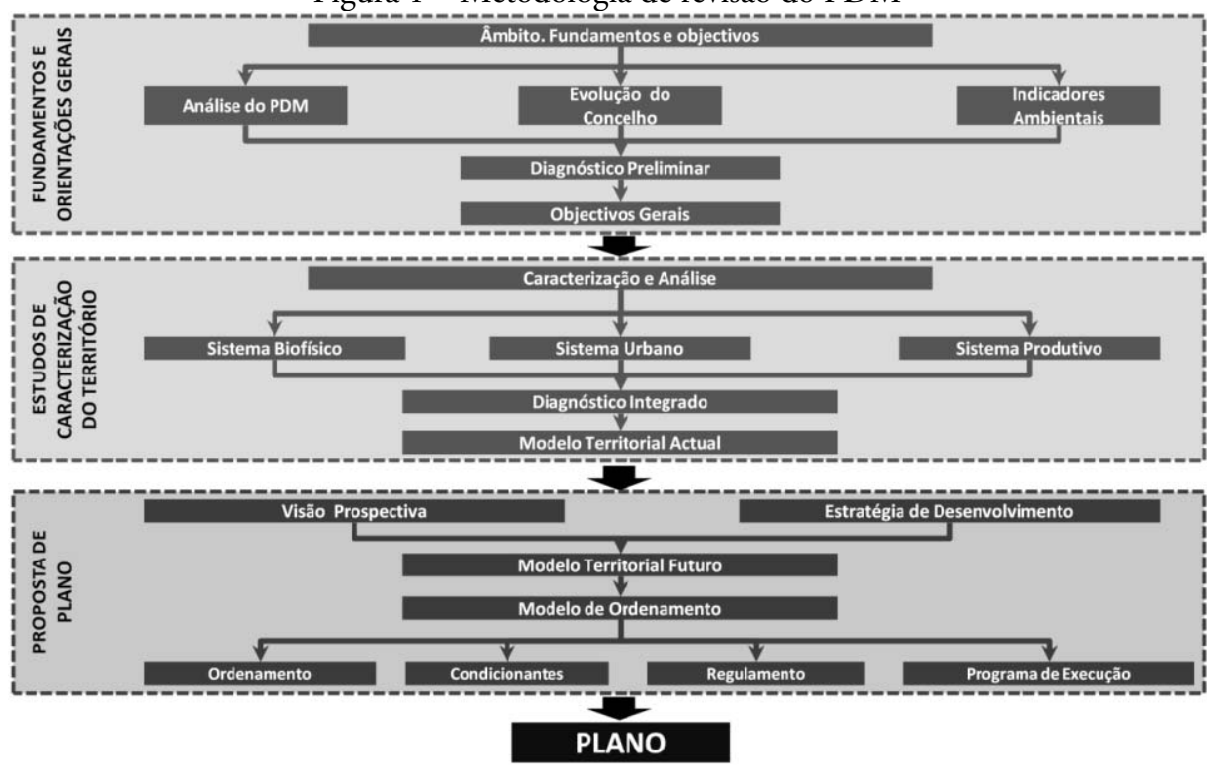

\section{O MODELO TERRITORIAL ACTUAL E FUTURO}

Uma das etapas do processo de revisão prende-se com a análise e caracterização da situação actual, a qual resulta na elaboração do diagnóstico, procedendo-se a partir deste à elaboraçáo do Modelo Territorial Actual. O Modelo Territorial deve ser entendido como uma abstracçáo mediante a qual se identificam e valorizam as várias componentes e relaçóes de uma realidade (territorial) complexa, permitindo uma interpretação sintética dessa realidade, da sua organização e funcionamento (Pujadas et al., 1998).

A principal finalidade é construir um esquema de organização do território, apresentando-se como um referencial genérico que, tendo em conta os objectivos globais de ordenamento e de desenvolvimento e as conclusóes que advêm do diagnóstico efectuado, permita sustentar a definição de objectivos e estratégias territoriais. Trata-se de uma interpretação da realidade que visa servir de guia orientador para a formulação de estratégias específicas de actuação em cada parte do território municipal e de potenciação máxima das sinergias entre os vários espaços. Com a sua definição e interpretação pretende-se esquematizar a organiza- 
ção territorial, colocar de parte as diferenças de áreas homogéneas e passar a uma abstracção do território, sintetizando o funcionamento e a organização do território municipal. O Modelo Territorial Actual traduz espacialmente as vocaçóes territoriais e os principais perfis do sistema urbano municipal, apresentando como base as especializações físicas do território através da identificação dos principais valores/recursos dos potenciais naturais e biofísicos existentes e da especialização funcional actual dos centros urbanos bem como dos principais eixos de articulação e respectivos fluxos dominantes. A elaboração do Modelo Territorial é feita em duas fases: primeiro elabora-se o esquema funcional, que agrega os sistemas estruturantes (biofísico, urbano, produtivo de base territorial), e traduz o modo de organizaçáo e de funcionamento do território; de seguida, procede-se à elaboração do esquema global, traduzindo espacialmente o diagnóstico e a estrutura de ocupação e uso do território.

Com o Modelo Territorial Futuro representa-se espacialmente a visão, ambição, desígnios e opçóes estratégicas que sintetizam o rumo a imprimir às políticas municipais de desenvolvimento e ordenamento territorial num horizonte de 10 anos. É, pois, um novo mapa que se desenha para o município. Esta formulação prospectiva e voluntarista do modelo futuro ancora-se na análise e diagnóstico, nos cenários de desenvolvimento e ainda na visão, ambição, desígnios e opções estratégicas (figura 2).

A construçâo do Modelo Territorial Futuro é feita em dois tempos: no primeiro elabora-se o esquema funcional com os sistemas estruturantes; no segundo, procede-se à elaboração do esquema global de ordenamento, onde se define a estrutura de ordenamento do território (classes e categorias de uso do solo, rede viária, solos afectos à estrutura ecológica municipal, unidades operativas de planeamento e gestão e condicionantes diversas), e que traduz a evolução preconizada para a estrutura de ocupação e uso do território municipal. O esquema funcional futuro visa identificar e explicitar a estrutura geral da organização do território, as respectivas componentes e suas relaçóes. Deve ser entendido como uma representação das várias componentes e relaçôes de uma realidade complexa e das opçôes subjacentes à configuração dos desígnios, no quadro da estratégia de desenvolvimento territorial, e não uma justaposição dos mesmos.

Figura 2 - Metodologia de elaboração do Modelo Territorial Futuro

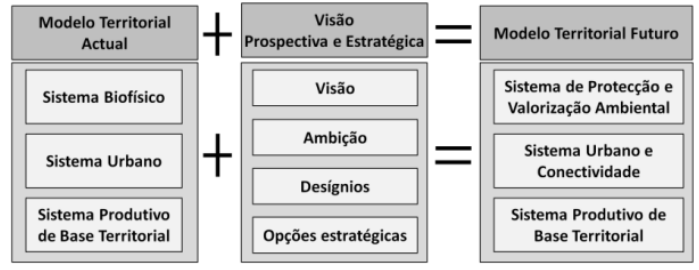

Também no modelo futuro, os principais componentes correspondem aos sistemas estruturantes: protecção e valorização ambiental (Estrutura Ecológica Municipal; áreas de protecçáo especial: Reserva Ecológica Nacional, Reserva Agrícola Nacional, Rede Natura 2000; áreas ameaçadas por riscos tecnológicos e naturais); urbano, de acessibilidade e conectividade (aglomerados urbanos hierarquizados; articulação territorial traduzida em fluxos e áreas de influência; rede viária hierarquizada; bem como as conectividades 
externas actuais ou a potenciar); produtivo de base territorial (vocaçóes económicas territoriais; infra-estruturas e unidades produtivas de maior expressão).

\section{O SIG MUNICIPAL DE APOIO À REVISÃO DO PDM}

Os processos de Planeamento e Ordenamento do Território exigem uma grande quantidade de dados e de informaçáo especializada capaz de assegurar uma análise sistémica da realidade municipal. A revisão de um instrumento de gestão do território como o PDM obriga a uma actualizaçáo profunda da informaçáo relativa aos vários sistemas que compóem o território, e, porque é de território que se trata, a grande maioria dessa informação é de natureza geográfica. Um SIG configura-se assim como um instrumento indispensável no apoio técnico aos trabalhos de revisão destes instrumentos de planeamento, permitindo a compilação e organizaçáo de grandes quantidades de dados geográficos e alfanuméricos em bases de dados estruturadas assim como a sistematização de processos de análise territorial mais rigorosos fruto das potencialidades inerentes à espacialização da informação (Aronoff, 1989; Machado, 2000; Ramos et al., 2001).

O SIG foi desenvolvido sob a plataforma ArcGis9 da ESRI integrando uma base de dados geográficos e alfanuméricos (File Geodatabase) gerida centralmente e disponibilizada aos técnicos que integram a equipa de revisão. Esta base de dados integra informação de diversas fontes oficiais, entre outras: Instituto Geográfico Português; Centro Nacional de Informação Geográfica; Autoridade Florestal Nacional; Instituto da Conservação da Natureza e Biodiversidade; Instituto Nacional de Estatística; Agência Portuguesa do Ambiente. Os elementos recolhidos nestas fontes encontram-se em variados formatos e escalas que carecem de harmonização e compatibilização.

A escala de revisão e de produção cartográfica de um PDM é normalmente 1:10 000, no entanto a informação necessária para a sua revisão varia entre a escala 1:2 000 (planimetria das áreas urbanas) à escala 1:1.000.000 (Atlas do Ambiente Digital). Para além das diferenças de escala dos dados existe também a necessidade de compatibilizar informação geográfica em diferentes formatos: vectorial, matricial e até mesmo informação analógica (papel) indispensável ao processo de revisão. O sistema desenvolvido é um SIG vectorial embora integre alguns elementos matriciais fundamentais nomeadamente os ortofotomapas actualizados. Os restantes elementos matriciais e analógicos foram convertidos em formato vectorial seguindo os processos descritos na figura 3 .

Uma das principais funçôes do SIG desenvolvido é assegurar a inventariação exaustiva do território municipal. A elaboração deste inventário permite descrever e caracterizar objectivamente o território assim como percepcionar o comportamento do mesmo nas mais variadas componentes. $\mathrm{O}$ inventário agrega os elementos que caracterizam o território nas suas diversas componentes: meio físico, ambiental, cultural, económico, social, etc., assim como as principais redes de infra-estruturas (saneamento básico, rede viária, telecomunicaçóes, etc.) e os principais equipamentos, serviços e unidades produtivas. Toda a informação encontra-se organizada em "layers" estruturados em áreas temáticas correspondentes aos sistemas territoriais definidos e uma área temática de base que agrega as componentes de informação geográfica transversais aos vários sistemas do território (limites administrativos, planimetria, altimetria, etc.) (Figura 4). 
Figura 3 - Processos de conversão de informação para introdução no SIG Conversão analógico-digital (vectorial)

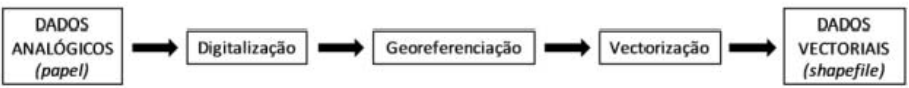

Conversão raster-vector

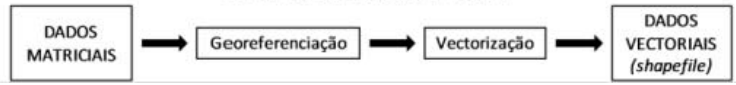

Figura 4 - Excerto da estrutura de dados geográficos do SIG desenvolvido

\begin{tabular}{|c|c|c|c|c|}
\hline $\begin{array}{l}\text { Limite Concelho } \\
\text { (área) }\end{array}$ & $\begin{array}{l}\text { ABASTECIM_P } \\
\text { (Ponto) }\end{array}$ & $\begin{array}{l}\text { Rede Viária } \\
\text { (linha) }\end{array}$ & $\begin{array}{l}\text { PONT_COTADOS } \\
\text { (ponto) }\end{array}$ & ZPE (área) \\
\hline $\begin{array}{l}\text { ID_NUT III (Short) } \\
\text { DTCC (Text) } \\
\text { NOME (Text) }\end{array}$ & $\begin{array}{c}\text { ID (Long) } \\
\text { TIPO (Text) } \\
\text { DTCCFR (Long) } \\
\text { TRATAMENTO (Text) } \\
\text { COORD_X (Double) }\end{array}$ & \begin{tabular}{|c|} 
ID (Short) \\
TIPO (Text) \\
CLASS (Text) \\
NOME (Text) \\
COD_RUA (Long)
\end{tabular} & $\begin{array}{l}\text { CURVAS NIVEL } \\
\text { (linha) }\end{array}$ & $\begin{array}{l}\text { OBJECTID (Long) } \\
\text { SITE_NAME (Text) } \\
\text { SITE_CODE (Text) } \\
\text { PUBLICACAO (Text) } \\
\text { AREA_HA (Double) }\end{array}$ \\
\hline $\begin{array}{l}\text { Limite Freguesia } \\
\text { (área) }\end{array}$ & COORD_Y (Double) & $\begin{array}{l}\text { HIERARQUIA (Short) } \\
\text { ESTADO_CONS (Text) }\end{array}$ & $\begin{array}{c}\text { TIPO (Text) } \\
\text { COTA(Double) }\end{array}$ & APS (área) \\
\hline $\begin{array}{l}\text { DTCC (Text) } \\
\text { DTCCFR (Text) } \\
\text { NOME (Text) }\end{array}$ & $\begin{array}{l}\text { SANEAMENTO_P } \\
\text { (Ponto) }\end{array}$ & $\begin{array}{l}\text { EXTENSĀO (Double) } \\
\text { DRENAGEM (Boolean) } \\
\text { ABASTECIM (Boolean) }\end{array}$ & $\begin{array}{l}\text { REDE HIDRO } \\
\text { (área) }\end{array}$ & $\begin{array}{c}\text { ID (Long) } \\
\text { CLASSIF (Text) }\end{array}$ \\
\hline $\begin{array}{c}\text { Toponimia } \\
\text { Lugares (ponto) }\end{array}$ & $\begin{array}{c}\text { ID (Long) } \\
\text { TIPO (Text) } \\
\text { DTCCFR (Long) }\end{array}$ & $\begin{array}{l}\text { AECOM (Boolean) } \\
\text { GAS (Boolean) }\end{array}$ & $\begin{array}{c}\text { LENGTH (Double) } \\
\text { CODRIOS (Text) } \\
\text { DESIGNACAO (Text) } \\
\text { TPO (Text) }\end{array}$ & $\begin{array}{l}\text { NOME (Text) } \\
\text { NOME1 (Text) } \\
\text { CLASS1 (Text) } \\
\text { áREA_HA (Double) }\end{array}$ \\
\hline $\begin{array}{l}\text { ID (Long) } \\
\text { DTCCFR (Text) } \\
\text { NOME (Text) }\end{array}$ & $\begin{array}{l}\text { COORD_X (Double) } \\
\text { COORD Y (Double) }\end{array}$ & Edificios (área) & $\begin{array}{l}\text { PER_FLORESTAL } \\
\text { (área) }\end{array}$ & Sítios (área) \\
\hline cos90 (área) & $\begin{array}{c}\text { TELECOM_P } \\
\text { (Ponto) }\end{array}$ & \begin{tabular}{|c|} 
ID (Long) \\
NOME (Text) \\
TIPO (Text)
\end{tabular} & $\begin{array}{c}\text { PF_MN_(Text) } \\
\text { COD (Double) } \\
\text { Área_final (Double) }\end{array}$ & $\begin{array}{l}\text { CLASS (Double) } \\
\text { CODIGO (Text) } \\
\text { FASE (Short) } \\
\text { NOME (Text) } \\
\text { AREA HA (Double) }\end{array}$ \\
\hline $\begin{array}{c}\text { GOC101_(Double) } \\
\text { GOC101_ID (Double) } \\
\text { AREA_HA (Float) } \\
\text { LEG (Text) }\end{array}$ & $\begin{array}{c}\text { ID (Long) } \\
\text { TIPO (Text) } \\
\text { DTCCFR (Long) } \\
\text { TRATAMENTO (Text) }\end{array}$ & $\begin{array}{l}\text { COTA_P_A (Double) } \\
\text { COTA_CERCEA (Double } \\
\text { ALTURA (Double) } \\
\text { ALT CERCEA (Double) }\end{array}$ & SOLOS (área) & CUMA (área) \\
\hline $\begin{array}{l}\text { LEG1 (Text) } \\
\text { LEG2 (Text) }\end{array}$ & $\begin{array}{l}\text { COORD_X (Double) } \\
\text { COORD_Y (Double) }\end{array}$ & $\begin{array}{c}\text { USO_DOM (Text) } \\
\text { ESTADO_CONS (Text) }\end{array}$ & $\begin{array}{c}\text { SOLOS8_1_1 (Double) } \\
\text { CODE (Tert) }\end{array}$ & $\begin{array}{c}\text { ID (Double) } \\
\text { GRIDCODE (Double) }\end{array}$ \\
\hline
\end{tabular}

O SIG desenvolvido garante a possibilidade de se estabelecerem relaçóes e processos que articulem e conjuguem os diferentes "layers" de modo a serem produzidos diagnósticos territoriais adequados e multidisciplinares nas componentes de análise consideradas e que permitam elaborar cenários alternativos de suporte aos processos de decisão assim definir os modelos territoriais (Rivas Sanz et al.,1998). Apresentam-se de seguida as metodologias utilizadas na definição das componentes do Modelo Territorial Actual.

\subsection{Sistema Biofísico}

No Sistema Biofísico identificam-se os principais valores e recursos naturais do município, que deverão garantir a sustentabilidade económica, enquanto suporte das principais actividades laborais, quer a sustentabilidade ambiental e ecológica através da protecçáo de espaços de reconhecido valor, bem como a sua valorização através da definição de usos compatíveis que permitam a ocorrência de outras actividades com potencial municipal.

No inventário e caracterização biofísica é realçada a importância de uma análise transversal, em oposição a uma descrição exaustiva das variáveis biofísicas. De forma a compreender o funcionamento ecológico do concelho, a caracterização biofísica desenvolve-se sob três vertentes: a configuraçáo física do meio, as condiçóes naturais e as condiçóes ambientais. 
Numa fase posterior identificam-se as unidades territoriais, com base numa leitura sintética do contexto biofísico e das dinâmicas presentes em porçôes individualizadas do território (figura 5). É possível identificar unidades territoriais que expressam a contribuição dos diferentes descritores na criação de condiçóes naturais e ambientais diferenciáveis. O fundamento deste tipo de análise é avaliar em que medida o meio biofísico determina a distribuição das actividades humanas.

Procura-se uma aproximação sucessiva à estrutura biofísica baseada na interacção entre os diversos descritores. Esta inicia-se com a análise da configuraçáo do meio como suporte físico para a instalação das espécies. Seguidamente identificam-se as condiçóes prevalecentes em termos de características climáticas, solo e vegetação. Em função dessas características o Homem ocupa o território de uma forma diferenciada criando uma organizaçáo espacial determinada pelas condiçóes naturais. Identificam-se ainda as áreas mais sensíveis que deverão ser alvo de forte protecção, assim como as áreas de conflitos e ameaças que deverão ser alvo de processos cuidados quer de protecção, quer de requalificação ambiental no futuro.

Figura 5-Metodologia para a definição do Sistema Biofísico

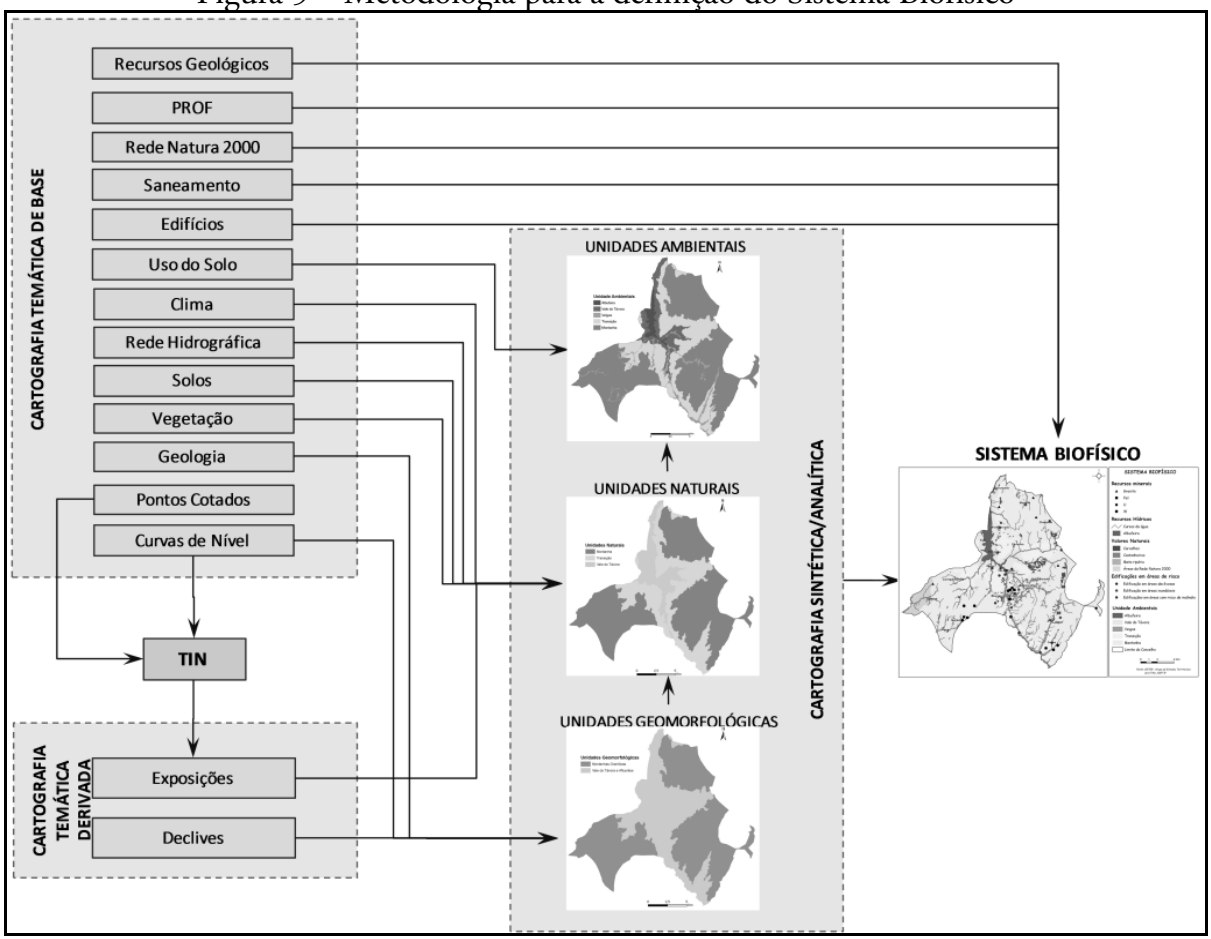

\subsection{Sistema Urbano}

O Sistema Urbano é organizado em "nós”, “fluxos” e "articulação territorial”. Os dois primeiros integram os aglomerados, sobre os quais é feita uma caracterização quer do ponto de vista da morfologia e topologia da ocupação do solo urbano, quer do nível de 
infra-estruturação e dotação de equipamentos e serviços. Esta caracterização permite estabelecer uma hierarquia do sistema urbano actual e perceber quais os principais problemas ao nível das dinâmicas de crescimento das manchas urbanas (figura 6).

No que diz respeito à rede de equipamentos e serviços é feito um inventário das funçôes existentes nos vários aglomerados do município, de modo a termos uma percepção dos níveis de concentração e polarização existentes no território municipal. Os fluxos, por seu lado, integram e caracterizam os serviços que asseguram a ligação entre os vários nós da rede urbana municipal, nomeadamente os de transporte, permitindo averiguar sobre a acessibilidade externa do município, avaliando os níveis de acesso das freguesias aos principais corredores rodoviários e aos principais pólos urbanos da região, e interna, avaliando a qualidade da estrutura física de suporte ao transporte e a periodicidade dos serviços de transporte entre os vários nós e os padróes de mobilidade dos habitantes.

Figura 6 - Metodologia de definição do Sistema Urbano

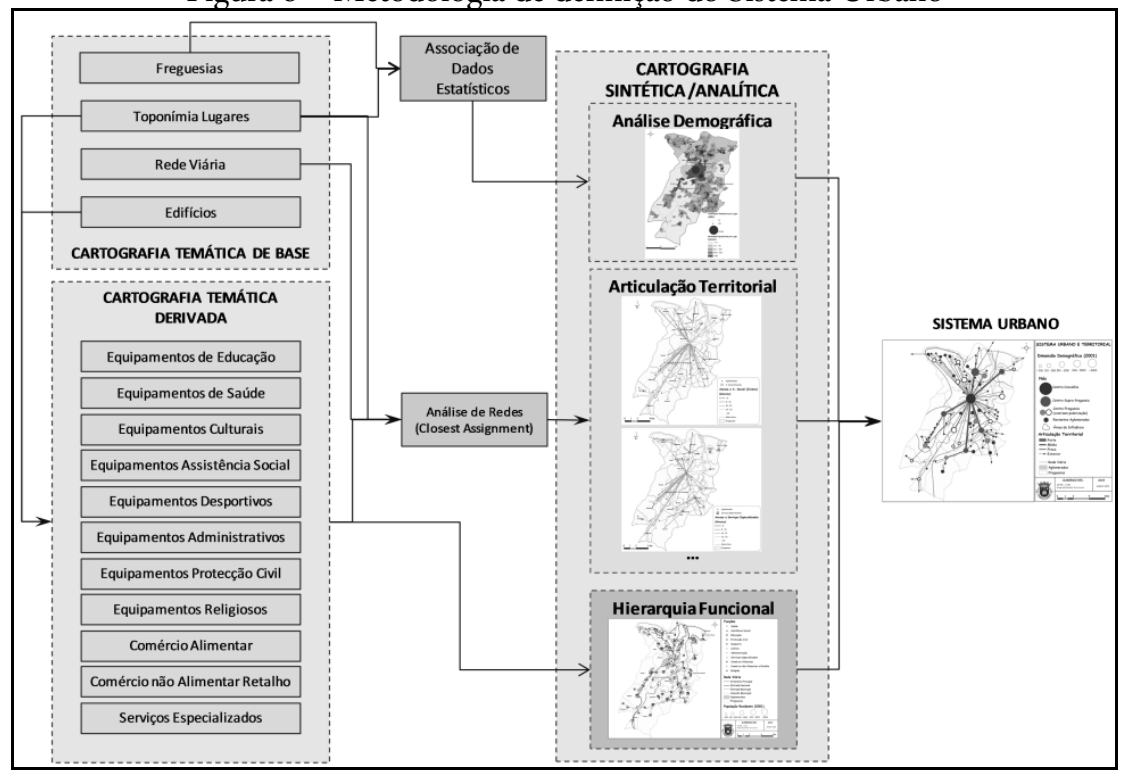

Por fim, e ao nível da articulação territorial, procede-se à avaliação das áreas de influência dos equipamentos e serviços para as principais funçóes existentes nos nós, com o objectivo de definir as principais articulaçóes urbanas, a sua natureza e intensidade, bem como identificar as zonas mais precárias ao nível do acesso a um conjunto considerado mínimo de funçóes e serviços indispensáveis para garantir uma qualidade de vida aceitável.

\subsection{Sistema Produtivo de Base Territorial}

No Sistema Produtivo de Base Territorial procede-se à análise dos sectores de actividade associados ao território. Ao nível da base produtiva territorial são identificadas as ocupaçóes dominantes do solo de modo a identificar e delimitar as grandes áreas de 
produção primária - áreas agrícolas, florestais, etc. Para esta identificação é utilizada a Carta de Ocupação do Solo (COS’90) procedendo-se a uma actualização das classes através da recorrendo à fotointerpretação dos ortofotomapas recentes. Ao nível do sector secundário são identificados, com base no edificado, os principais pólos industriais e unidades de produção. É ainda caracterizada a oferta turística e identificam-se os recursos naturais e patrimoniais com maior potencial turístico (figura 7).

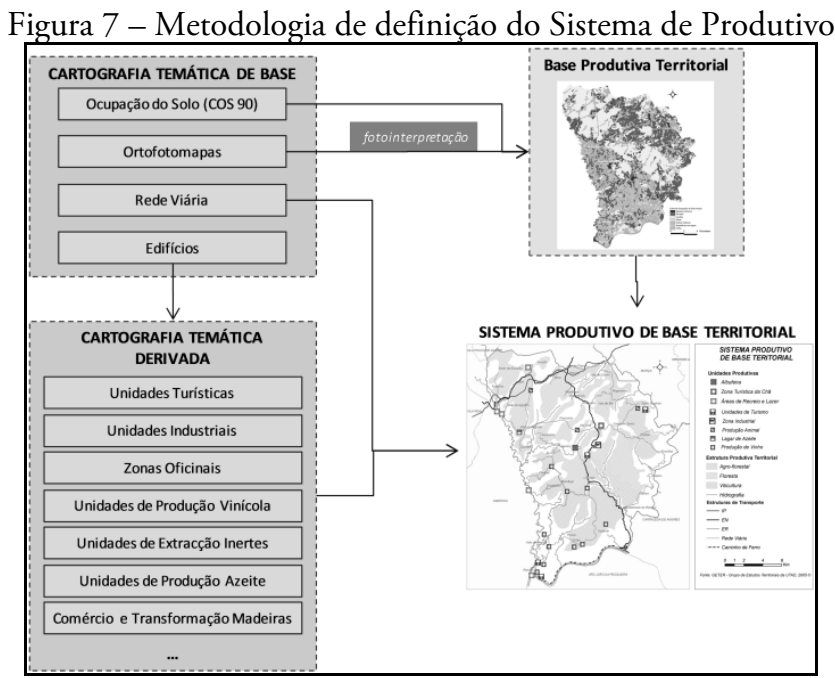

\subsection{Esquema do modelo territorial actual}

Após a definição dos sistemas estruturantes do modelo territorial, procede-se à elaboração do esquema global, onde se define a estrutura de ordenamento do território municipal (figura 8), traduzindo espacialmente o diagnóstico e a estrutura de ocupação e uso do território, assente nos sistemas que agregam os recursos e organizam o funcionamento do território.

\section{CONCLUSÃO}

Dada a complexidade dos processos de ordenamento territorial, não é hoje possível suportar um qualquer exercício de planeamento físico sem recorrer aos SIG, os quais permitem, pela sua natureza e concepçáo, integrar de forma eficiente toda a informação disponível e necessária para a análise dos problemas territoriais e permitem disponibilizar de modo integrado dados multissectoriais, com diversas origens e escalas, facilmente actualizáveis e relacionáveis entre si.

O seu contributo para a renovação dos exercícios de planeamento e de ordenamento do território é indiscutível, nomeadamente ao permitirem uma maior profundidade e abrangência das análises e propostas técnicas, um maior rigor na selecção de alternativas e uma participação mais activa na elaboração e gestão dos planos. 
Figura 8 - Definição do Esquema do Modelo Territorial Actual

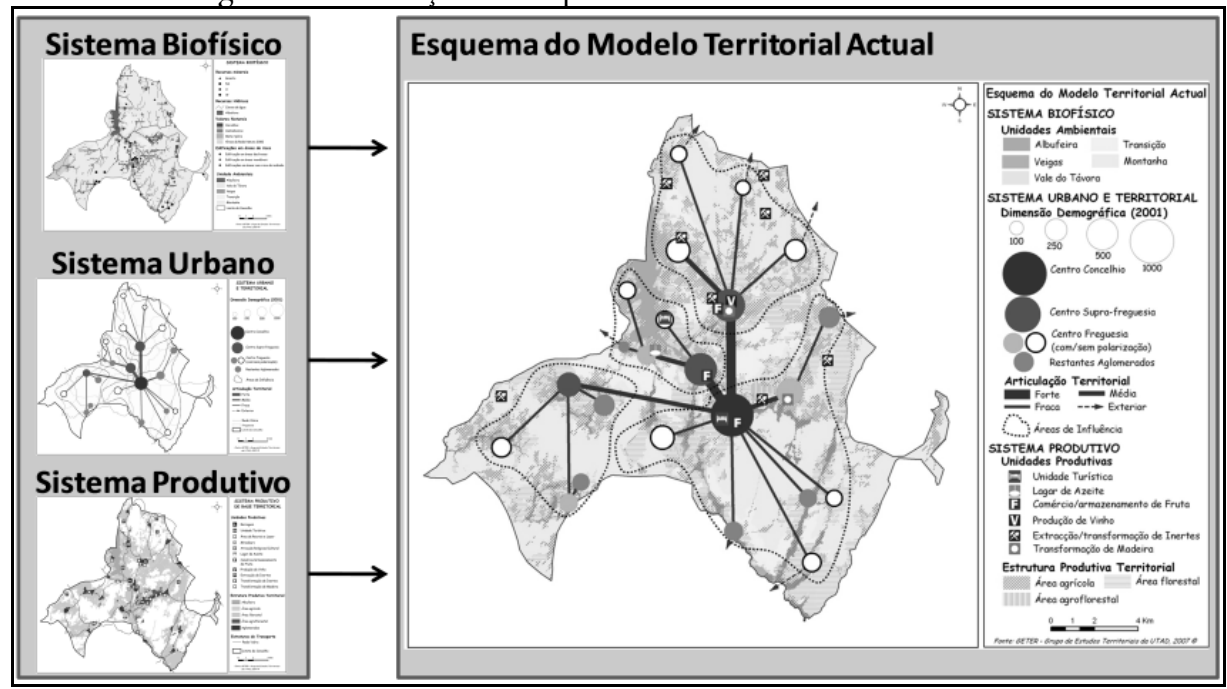

\section{REFERÊNCIAS BIBLIOGRÁFICAS}

Aronoff, S. 1989, Geographic Information Systems: A management Perspective, Ottwa, WDL Publications.

Machado, J. 2000, A emergência dos SIG na análise e organização do espaço, Lisboa, Fundação Calouste Gulbenkian. Mclouhhlin, J. 1969, Urban and Regional Planning: a systems approach, Faber and Faber, London.

Orea, Domingo G. 2008, Ordenación Territorial, Ediciones Mundi-Presa, 2a ed, Madrid, 766p.

Pujadas, Romá et al. 1998, Ordenación y Planificación Territorial, Madrid, Ed. Síntesis.

Ramos, L. et al. 2001, "Uma experiência de aplicação dos SIG ao planeamento e ordenamento dos territórios rurais", I Congresso en Las Arribes del Duero, Salamanca.

Rivas Sanz, J. L. et al. 1998, Directrices de Ordenación Territorial de Valladolid y Entorno (DOTVAENT). Valladolid, Consejería de Medio Ambiente y Ordenación del Territorio, Junta de Castilla y León. 